\title{
BOOKS
}

\section{The Double Helix}

by James D. Watson

Atheneum $\$ 5.95$

reviewed by Robert $L$. Sinsheimer, chairman of the division of biology

This is a saddening book, for it reminds us of that which we would rather forget-that in homo sapiens brilliance need not be coupled with compassion, nor ambition with concern.

In reality this is two books. One is an account-lucid, honest, suspenseful-of the scientific events that led to the deduction of the molecular structure of DNA, which at one stroke provided a clear chemical basis for the results of 50 years of genetics and at the same time constituted the central support about which the whole structure of molecular biology could be built. Because it is in many ways a typical story of scientific discovery-with false trails, the fortuitous combinations of ideas, the ex-post-facto-obvious nature of the solution-with all the drama heightened by the importance of the goal-it could well serve as a model text for initiation of the young, were it not for the second book. It is fascinating even now to look back and to note how many of the essential facts were available (the Chargaff rules of the molar equalities of adenine and thymine and of guanine and cytosine, the knowledge from x-ray data of a helical structure with the phosphate-sugar backbone on the outside, the suggestion of complementarity as the necessary structura] basis of gene replication); and yet the true solution, though but a small step from these, was by no means obvious.

This story is of such interest that one can overlook its atypical aspects, that Watson and Crick were relying upon cadged data from the x-ray studies of Franklin and Wilkinsoverheard in seminars, pried out in conversations, even provided by Max Perutz from a privileged report. Or the somewhat bogus suspense provided-repeatedly-by the synthetic race with the demigod Pauling. "Caltech's fabulous chemist, Linus Pauling, was not subject to the confines of British fair play. ... Our first principles told us that Pauling could not be the greatest of all chemists without realizing that DNA was the most golden of all molecules. . . . We had to face the bleak situation that the world authority on the structural chemistry of ions was Linus Pauling himself. ... Then it would be obvious to the world that Pauling was not the only one capable of true insight into how biological molecules were constructed."

The second book, however-interwoven with the first-is a description of the private world of J. D. Watson during these historic events. And this is unbelievably mean in spirit, filled with the distorted and cruel perceptions of childish insecurity. It is a world of envy and intolerance, a world of scorn and derision. This book is filled with character assassination, collective and individual, direct and indirect. Even worse is the evidence that Watson believes the rest of humanity-save for the muddle-headed-sees this same world.

It is a world of intense ambitionfor the mundane prize, not the advancement of truth nor the service of humanity. Thus, " : . Francis [Crick] and I went over to the Eagle. The moment its doors opened for the evening, we were there to drink and toast to the Pauling failure. Instead of sherry I let Francis buy me a whiskey. Though the odds still appeared against us, Linus had not yet won his Nobel."
His mentor, Luria, is portrayed as an amiable simpleton. "He [Luria] positively abhorred most chemists, especially the competitive variety out of the jungles of New York City. Kalckar, however, was obviously cultivated..."

Of Chargaff: "Chargaff as one of the world's experts on DNA was at first not amused by dark horses trying to win the race. Only when John [Kendrew] reassured him by mentioning that I was not a typical American did he realize he was about to listen to a nut." Now everyone knows that J. D. Watson, Nobel prizewinner, is not and never was a nut, so what conclusion must one draw about Chargaff?

Or Randall: "Finding himself [Randall] overcommitted he had decided to send Maurice [Wilkins] instead. If no one went it would look bad for his Kings College lab. Lots of scarce Treasury money had to be committed to set up his biophysics show and suspicions existed that this was money down the drain."

Of biologists: "But even so they [biochemists] knew more than the majority of biologists. In England, if not everywhere, most botanists and zoologists were a muddled lot. Not even the possession of university chairs gave many the assurance to do clean science; some actually wasted their efforts in useless polemics about the origin of life or how we know that a scientific fact is really correct."

Of geneticists: "This is not to say that the geneticists themselves provided any intellectual help .... All that most of them wanted out of life was to set their students onto uninterpretable details of chromosome behavior or to give elegantlyphrased, fuzzy-minded speculations over the wireless on topics like the role of the geneticist in this transitional age of changing values."

continued on page 6 


\section{Books ... continued}

Of scientists in general: "Many were cantankerous fools who unerringly backed the wrong horses. One could not be a successful scientist without realizing that in contrast to the popular conception supported by newspapers and mothers of scientists, a goodly number of scientists are not only narrow-minded and dull, but also just stupid."

Of Caltech chemists: "A number of his [Pauling's] colleagues quietly waited for the day when he would fall flat on his face by botching something important."

I could go on, but why bother. Apparently motive, like beauty, is in the eye of the beholder.

Several of the reviews of this book have commented on the strange vignette of the foreword in which Watson, climbing up a ski slope, sees W. Seeds, a collaborator of Wilkins, hiking down. Watson pauses to talk to Seeds, but the latter, on noticing Watson, merely remarks, "How's Honest Jim?" and passes on. These reviewers have felt that Watson, deeply stung by remarks of this sort, has written The Double Helix as an apologia. On the evidence of this book, I disagree. Watson is Honest Jim, believing he sees the world true, and "telling it like it is."

It is perhaps an interesting psychological question, if indeed these two books-the components of The Double Helix-are not in themselves complementary; if indeed the structure of DNA would have been discovered in this way had it not been for both the slanting brilliance and the skewed personality of J. D. Watson. Probably not. Although the discovery would not have been long delayed, it would have developed in a more conventional manner out of the x-ray studies of Wilkins, the model building of Pauling, the biochemistry of Kornberg. Ingenuity and clutching ambition bought a year or two in time-and fame.
But what will be the view of the scientific endeavor to be gained by the high school student who will surely read this? He will learn that it is a clawing climb up a slippery slope, impeded by the authority of fools, to be made with cadged data and a resolute avoidance of profound learning, with malice toward most and with charity for none. Is this really true? Not in my experience. Rather, it is a caricature and will do far more harm than we can soon undo with sincere words about the humane and esthetic qualities of science.

\section{Numerical Methods for Two-Point Boundary Value Problems}

by Herbert B. Keller

Blaisdell Publishing Company....\$7.50

reviewed by Martin $H$. Schultz, associate professor of mathematics

Two-point boundary value problems have been important in engineering and science since the advent of the calculus. Recently these problems have become of prime importance in many engineering applications because of the development and growing importance of optimal control theory. Since the solutions of most of the two-point boundary value problems cannot be obtained or approximated by analytical methods, efficient numerical methods for approximating these solutions are necessary.

In his excellent monograph Herbert Keller, who is professor of applied mathematics at Caltech, introduces, describes, and analyzes three practical numerical methods for approximating the solutions of general nonlinear second-order problems and linear second-order eigenvalue problems. The first two methods, the initial-value or shooting method and the finite difference method, are also applied to problems for firstorder systems of nonlinear equations. Much of the material on the shooting method is new. In particu- lar, the first theoretical analysis of "parallel shooting" is given. The third method, integral equation techniques, is also analyzed for the first time. In addition, Keller adds an excellent chapter describing how the methods discussed in the text can be applied to some hard practical problems, even when the hypotheses needed for theoretical justification are not satisfied.

The book reads easily and can be understood by people with a background of advanced calculus, matrix theory, and elementary numerical analysis and differential equations.

\section{Analysis of Numerical Methods}

by Eugene Isaacson and Herbert B. Keller

John Wiley and Sons, Inc........\$11.95

reviewed by Martin $H$. Schultz, associate professor of mathematics

Since the advent of the electronic digital computer, numerical computing has become essential not only in engineering analysis but also in current scientific research. This excellent text, a collaboration between Dr. Keller and his former colleague, professor of mathematics at the Courant Institute of Mathematical Sciences, New York University, introduces and discusses in detail many of the basic numerical techniques which are in current use.

The topics covered include numerical linear and nonlinear algebra, approximation and interpolation theory, numerical integration, and difference methods for ordinary and partial differential equations. Moreover, an excellent introductory chapter introduces the reader to the important concepts of norms in finite-dimensional spaces, rounding error analysis, and well-posed computations. The level of discussion is such that the book is accessible to people with an advanced calculus and matrix theory background.

Unlike many other numerical continued on page 42 


\section{ALUMNI ASSOCIATION \\ CALIFORNIA INSTITUTE OF TECHNOLOGY \\ Pasadena, California}

BALANCE SHEET

June 30, 1968

Cash on Hand and in Bank

ASSETS

Investments:

Share in C.I.T. Consolidated Portfolio

Deposits in Savings Accounts

Investment Income Receivable

Postage Deposit, etc.

Furniture and Fixtures, at nominal value Total Assets

Accounts Payable

LIABILITIES, RESERVES AND SURPLUS

Deferred Income:

Membership Dues for $1968-69$ paid in advance $\$ 17,875.00$

Investment Income for 1968-69 from C.I.T.

Consolidated Portfolio (earned during 1967-68) : $5,912.60$

Life Membership Reserve:

Balance, July 1, 1967

Life Membership Dues received during 1967-68

Share of Gain on Disposal of Investments of

C.I.T. Consolidated Portfolio for 1967-68

Reserve for Directory:

Balance, July 1, 1967

1967-68 Appropriation

1967-68 Directory Expense

Surplus:

Balance, July 1, 1967

Excess of Expenses over Income for 1967-68

Total Liabilities, Reserves and Surplus

STATEMENT OF INCOME AND EXPENSES

For the Year Ended June 30, 1968

Dues of Annual Members

INCOME

Investment Income:

Share from C.I.T. Consolidated Portfolio

Interest on Deposits in Savings Accounts

Annual Seminar

Program and Social Functions

Miscellaneous

Total Income

EXPENSES

Subscriptions to Engineering and Science Magazine: Annual Members

Life Members

$\$ 15,300.25$

. $3,528.00$

Annual Seminar

Program and Social Functions

Directory Appropriation

Adminstration

Membership Committee

ASCIT Assistance

Total Expenses

Excess of Expenses over Income
$\$ \quad 3,844.49$

$73,562.84$

$22,061.09$

$195,623.93$

$5,912.60$

288.14

1.00

$\$ 20 \overline{05,670.16}$

$\$ \quad 658.14$

$23,787.60$

$\$ 122,901.81$

$43,200.00$

$7,461.03$

$\$ 3,305.79$

$3,000.00$

(299.62)

$\$ 3,219.13$

$(1,563.72)$

$1,655.41$

$\$ 205,670.16$

$173,562,84$

$6,006.17$
Perturbation Methods in

Applied Mathematics

by Julian D. Cole

Blaisdell Publishing Company ..\$9.50

reviewed by L. E. Fraenkel, Saul Kaplun Senior Research Fellow in Applied Mathematics

The theory describing the flow past bodies of a viscous fluid is a notoriously difficult one; the governing equations (Navier-Stokes) can be solved exactly and explicitly for only a few highly artificial cases, and approximation schemes invariably meet difficulties demanding and stimulating increasingly subtle mathematical techniques. In the years 1954-57 there appeared from Caltech four great papers which not only gave a fresh and clearer view of the various approximation schemes for very viscous and for nearly inviscid flow but which also systematized and extended significantly the mathematical technique implicit in Prandtl's boundary-layer theory: Indeed, these papers did much to provide the applied mathematician with new tools that have since then been applied to an astonishing variety of problems. These tools now form part of the subject

October 1,1968

CALVIN A. AMES

Certified Public Accountant 
known as "singular perturbations," a phrase used to describe methods for solving boundary- or initial-value problems which involve a small.parameter in such a way that the "obvious" expansion in terms of that parameter fails to approximate the desired solution throughout the physical domain. Saul Kaplun, to whom Lagerstrom and Cole attribute the principal ideas in this work, died in 1964 at the age of 39.

Fluid Mechanics and Singular Perturbations is in two parts. The first contains Kaplun's three published papers and preliminary drafts of intended papers on his approach to singular perturbations and on the lift at low Reynolds number of twodimensional bodies. The second part contains similar drafts of some of his extensive work on the problem of flow separation. The editors' work consisted of selection, of minor changes with respect to notation and errors of transcription, and of the provision of a most helpful commentary.

In 1955, when Julian Cole made his contribution to perturbation methods cited above, the techniques in question seemed the ultimate in sophistication (at least to this awestruck reader). Since then the subject has grown enormously, and at the same time "model" problems and simple methods of presentation have been devised so that now an almost elementary course on singular-perturbation methods is given to graduate students at many universities. Of course, plausibility and consistency arguments, rather than strict proofs, tend to be used. Perturbation Methods in Applied Mathematics is intended, and is most suitable, for such a course, and readers will be happy that the material largely complements rather than overlaps that in Van Dyke's book on a closely related subject.

The book is primarily a set of examples chosen to illustrate the application of boundary-layer techniques and of "two-variable" (one "fast," one "slow") expansion procedures to the approximate solution of initial- and boundary-value problems for differential equations (linear and nonlinear, ordinary and partial). The clarity and modesty of the presentation disguise the fact that much of the material, particularly that on two-variable methods, comes from recent research at Caltech by Julian Cole and his co-workers. The examples include, among much else: the deduction, by simple means, not only of the limit cycle of a van der Pol oscillator with small damping but also of the progress from the initial conditions to that cycle; a novel treatment of the Sturm-Liouville equation with a large parameter and a turning point; a rather complete discussion of the role of "subcharacteristics" when the limiting form of an elliptic or hyperbolic, second-order, partial differential equation is of the first order, the subcharacteristics being the characteristics of this reduced equation; and applications to viscous flow, compressible flow past thin aerofoils, magnetohydrodynamic pipe flow, and elastic shell theory.

In each case the forms of the expansion and stretching transformation, which are seldom obvious a priori, are deduced lucidly and carefully from the physics of the problem and the structure of its equation; and features common to diverse problems are emphasized. The approximate solution is then pursued relentlessly and skillfully until a complete picture emerges. $\square$
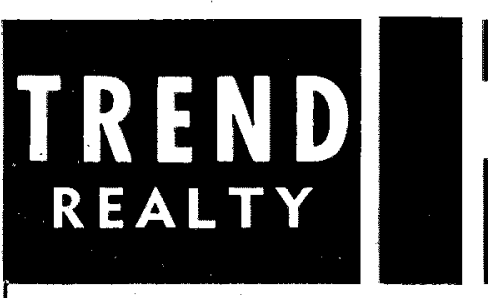

COMPLETE REAL ESTATE SERVICE HAWAIIAN ACREAGE

\section{MEMORANDUM}

To: The Caltech Community

From: Victor M. Lozoya

Now that summer is over, most of us are ready to take care of business matters that were laid aside during the warm months.

We hope yours was a pleasant summer and that you have happy vacation memories to last until next year. No doubt some of you visited or revisited the Hawaiian Islands, and are still thrilling to the natural beauty and aloha spirit you found there. You probably read in West Magazine (L. A. Times, August 24,1968 ) of the fantastic development now taking place on the Big Island of Hawaii. The article refers to the Kona Coast as "the Gold Coast of Hawaii," and goes on to predict that this area will "outWaikiki Waikiki." There is no doubt that Hawaiian land offers an unusual investment opportunity.

Speaking of the Islands, we still have a few one-acre lots to offer on the Kona Coast. These are excellent lots and can be purchased for as little as $\$ 1440-\$ 280$ down and $\$ 15$ monthly.

We are also proud to offer a parcel of 20 choice acres near Hilo, across the road from a major subdivision, and close to Highway 13. These are level acres with a fine ocean view, and the parcel is offered at $\$ 35,000$ with terms available.

If you need assistance in buying or selling a home, or in property rental, we will be happy to serve you.

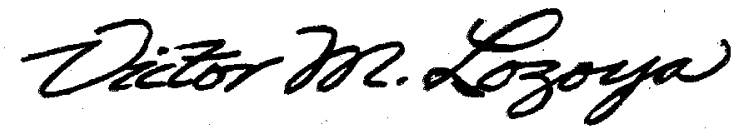

